\title{
Studi Alternatif Campuran Aspal Beton AC WC dengan Menggunaan Pasir Seruyan Kabupaten Seruyan Kalimantan Tengah
}

\author{
Endang Kasiati, Rachmad Basuki, Denny Setiawan \\ Program Studi Diploma Teknik Sipil FTSP ITS, Surabaya \\ Email:en_kas@ce.its.ac.id
}

\begin{abstract}
Seruyan District as one of the new districts in the province of Central Kalimantan. Pavement structure that is prevalent in Central Kalimantan Seruyan District is flexible pavements. Many aspects of flexible pavement structure should be reviewed, one of which is material. Materials are often imported from other areas. This is certainly not advantageous in terms of cost. This study was to examine the use of local materials as pavement materials one of which is natural sand Seruyan. This material will be utilized as fine aggregate mixture for Asphalt Concrete-Wearing Course (ACWC).

The purpose of this study was to determine the nature and characteristics of the AC-Wearing Course mix if using Seruyan natural sand as fine aggregate, especially the stability properties and characteristics/parameters of the Marshall test. The method used is a Marshall Test method, conducted using a variation of sand

The results of the study showed that the sand Seruyan marshall can be used as a mixture of asphalt concrete AC WC with a combination of $6 \%$ of fine aggregate sand fraction of Seruyan, $65.80 \%$ of Coarse aggregate fraction, $22.20 \%$ of fraction of Abu Stone, and $6 \%$ of filler fraction at optimum bitumen content of $5.27 \%$ by values of (stability, flow; VIM, VMA, VFA, MQ) met the standards of Highways Agency.
\end{abstract}

Keywords: seruyan sand, concrete asphalt, marshal.

Abstrak

Jaringan jalan mempunyai fungsi yang cukup penting dalam sistem transportasi, karena Kabupaten Seruyan sebagai salah satu kabupaten baru di Provinsi Kalimantan Tengah. Struktur perkerasan jalan yang lazim di Kabupaten Seruyan Propinsi Kalimantan Tengah adalah perkerasan lentur. Pada struktur perkerasan lentur banyak aspek yang harus ditinjau, salah satunya adalah material. Material sering didatangkan dari daerah tempat lain. Hal ini tentunya tidak menguntungkan dari segi biaya, penelitian ini adalah untuk menguji penggunaan material lokal sebagai bahan perkerasan yaitu pasir alam Seruyan yang akan di manfaatkan sebagai campuran agregat halus Laston Sebagai Lapis Aus Aspal Concrete Wearing Course (AC-WC).

Tujuan dari penelitian ini adalah untuk mengetahui sifat dan karakteristik campuran ACWearing Course jika menggunakan pasir alam seruyan sebagai agregat halus, yaitu khusus pada sifat stabilitas dan karakteristik pengujian Marshall. Metode penelitian yang digunakan adalah metode pengujian Marshall, dimana percobaan dilakukan dengan menggunakan variasi pasir.

Hasil penelitian marshall menunjukkan bahwa pasir Seruyan dapat digunakan sebagai bahan campuran beton aspal AC WC dengan hasil kombinasi agregatnya yaitu $6 \%$ untuk fraksi agregat halus Pasir Seruyan, 65,80\% untuk fraksi agregat Kasar, 22,20\% untuk fraksi Abu Batu, dan 6\% untuk fraksi filler pada kadar aspal optimum 5,27\% dengan nilai (stabilitas, flow; VIM, VMA, VFA, MQ) memenuhi standar Bina Marga.

Kata kunci: pasir seruyan, beton aspal, marshall.

\section{Pendahuluan}

Kabupaten Seruyan sebagai salah satu kabupaten baru di Provinsi Kalimantan
Tengah hingga saat ini masih belum banyak disentuh jaringan transporttasi darat. Struktur perkerasan jalan

Jurnal APLIKASI: Media Informasi \& Komunikasi Aplikasi Teknik Sipil Terkini Halaman 21 
yang lazim di Kabupaten Seruyan Propinsi Kalimantan Tengah adalah perkerasan lentur. Perkerasan lentur terdiri atas komposisi agregat kasar, agregat halus, aspal, dan material pengisi.

Pada struktur perkerasan lentur banyak aspek yang harus ditinjau, salah satunya adalah material. Dimana material ini sering didatangkan dari daerah tempat lain. Hal ini tentunya tidak menguntungkan dari segi biaya. Sampai saat ini belum banyak penelitian mengenai komposisi campuran yang dilakukan dengan menggunakan berbagai alternatif material, terutama penggunaan material lokal sebagai bahan perkerasan. Selain itu juga tercipta banyak potensi material yang dimanfaatkan salah satunya adalah pasir alam Seruyan, pasir seruyan memiliki deposit material yang cukup besar jumlahnya yakni sebanyak $\pm 9.000 .000 \mathrm{~m}^{3}$. Secara visual daerah yang dapat dieksploitasi diperkirakan mencapai luasan $4,5 \mathrm{~km}^{2}$ dengan ketebalan mencapai 2 m. Keuntungan selain mudah dieksploitasi adalah jaraknya relatif dekat dengan lokasi pekerjaan yaitu pada ruas jalan Arteri ibu kota kabupaten Seruyan Kuala Pembuang - ibu kota kabupaten Kotawaringin timur sampit $(\mathrm{km} 21-\mathrm{km}$ 50) tepatnya desa kalap kecamatan Seruyan hilir timur. Pasir Seruyan akan di manfaatkan untuk diteliti sebagai campuran agregat halus Laston Sebagai Lapis Aus Aspal Concrete - Wearing Course (AC-WC). Untuk itu perlu diteliti bagaimana sifat-sifat fisik Pasir Seruyan, antara lain gradasi, berat jenis, dan penyerapan air. Berapa proporsi campuran agregat halus dan agregat kasar agar memenuhi spesifik $A C W C$. Bagaimana pengaruh campuran pasir Seruyan pada Kadar Aspal Optimum terhadap sifat marshall sedangkan yang akan dianalisa adalah rongga terisi aspal (VFA), rongga dalam campuran (VIM), Rongga dalam Agregat (VMA), stabilitas (stability), kelelahan (Flow) dan Marshall Quotion (MQ). Pengujian dilakukan di Laboratorium Uji Material Program Diploma Fakultas Teknik Sipil dan Perencanaan ITS. Pengujian terhadap reaksi kimia yang terjadi pada campuran Laston Lapis Aus dan pengujian ekstrasi pada benda uji tidak dilakukan. Dengan pengujian ini semua diharapkan Pasir Seruyan sebagai agregat halus dapat dimanfaatkan untuk campuran Aspal Beton AC WC.

\section{Metodologi}

Langkah-langkah yang akan dilakukan selama penelitian tentang "Studi Penggunaan Pasir Seruyan sebagai campuran aspal beton ACWC" adalah sebagai berikut:

1. Persiapan bahan

2. Pengujian bahan:

a. Agregat halus: $\square$ Analisa saringan

$\square$ Berat jenis dan penyerapan air

b. Agregat kasar dan sedang:

$\square$ Abrasi

$\square$ Analisa saringan

$\square$ Berat jenis dan penyerapan air

c. Aspal:
$\square$ Penetrasi
$\square$ Berat jenis
$\square$ Titik lembek
$\square$ Titik nyala 
$\square$ Kehilangan berat

$\square$ Daktilitas

3. Perancangan proporsi agregat gabungan sesuai spesifikasi agregat AC WC 2010.

4. Menentukan kadar aspal rencana

5. Pembuatan benda uji (Briket) masing-masing 2 buah untuk Kadar Aspal Pb (-1,0\%; -0,5\%; $\mathrm{Pb} ;+0,5 \%$; $+1,0 \%$ )

6. Pengujian marsall

7. Pemeriksaan stabilitas, flow, FIM, FMA, VFA, dan MQ.

8. Penentuan kadar aspal optimum

9. Hasil pengamatan percobaan

10. Kesimpulan dan saran

\section{Hasil dan Pembahasan}

Data jaringan jalan di wilayah Kalimantan penelitiannya dilaksanakan di Laboratorium Uji Material Program Diploma Fakultas Teknik Sipil dan Perencanaan ITS Surabaya dengan menggunakan acuan standar uji Standar
Nasional Indonesia (SNI 03-1969-1990, SNI 03-1970-1990, SNI 03-2417-1991, SNI 03-2417-1991, dan SNI 06-24561991) atau American Association of State Highway and Transportation Officials (AASHTO).

Sampel agregat yang digunakan dalam penelitian ini Pengujian material dilakukan dengan acuan Standar Nasional Indonesia (SNI) dan AASHTO sebagai acuan. Apabila pengujian yang dimaksud tidak terdapat dalam SNI. Pengujian material meliputi: Sifat agregat (kasar, halus, dan Filler), serta pemeriksaan sifat fisik aspal Penetrasi 60/70.

Dari hasil pengujian aspal seperti Tabel 2 dilakukan berulang-ulang sampai memenuhi standart spesifikasi. Hasil pengujian gradasi agregat halus seperti pada Gambar 1 - 4.

Tabel 1. Hasil pengujian agregat

\begin{tabular}{|c|c|c|c|c|c|c|c|}
\hline No. & \multicolumn{2}{|l|}{ Pengujian } & \multicolumn{2}{|l|}{ Metoda } & Syarat & Hasil & Keterangan \\
\hline \multicolumn{8}{|c|}{ Agregat kasar PT. Merakindo Mix } \\
\hline 1 & \multicolumn{2}{|l|}{ Penyerapan air } & \multicolumn{2}{|l|}{ SNI 03-1969-1990 } & $\leq 3 \%$ & $2.650 \%$ & Memenuhi \\
\hline 2 & \multicolumn{2}{|l|}{ Berat jenis } & \multicolumn{2}{|l|}{ SNI 03-1970-1990 } & $\geq 2,5$ & 2.564 & Memenuhi \\
\hline 3 & \multicolumn{2}{|c|}{ Keausan / Los angeles abration test } & \multicolumn{2}{|l|}{ SNI 03-2417-1991 } & $\leq 40 \%$ & $23.60 \%$ & Memenuhi \\
\hline \multicolumn{8}{|c|}{ Agregat halus ( Pasir Seruyan ) } \\
\hline 1 & \multicolumn{2}{|l|}{ Penyerapan air } & \multicolumn{2}{|l|}{ SNI 03-1970-1990 } & $\leq 3 \%$ & $1.012 \%$ & Memenuhi \\
\hline 2 & \multicolumn{2}{|c|}{ Berat jenis } & \multicolumn{2}{|l|}{ SNI 03-1970-1990 } & $\geq 2,5$ & 2.519 & Memenuhi \\
\hline \multicolumn{8}{|c|}{ Agregat halus ( Abu Batu ) PT. Merakindo Mix } \\
\hline 1 & Penyerapan air & & \multirow{2}{*}{\multicolumn{2}{|c|}{$\begin{array}{l}\text { SNI 03-1970-1990 } \\
\text { SNI 03-1970-1990 }\end{array}$}} & $\leq 3 \%$ & $1.833 \%$ & Memenuhi \\
\hline 2 & Berat jenis & & & & $\geq 2,5$ & 2.577 & Memenuhi \\
\hline \multicolumn{8}{|c|}{ Filler ( Semen Portland ) } \\
\hline 1 & \multicolumn{2}{|l|}{ Berat jenis } & \multicolumn{2}{|l|}{ PB - $0202-76$} & $\begin{array}{l}0,5-9 \\
\mathrm{gr} / \mathrm{m}^{3} \\
\end{array}$ & 2.706 & Memenuhi \\
\hline \multicolumn{8}{|c|}{ Tabel 2. Hasil pengujian sifat aspal } \\
\hline \multirow{2}{*}{ No. } & \multirow{2}{*}{ Pengujian } & \multirow{2}{*}{\multicolumn{2}{|c|}{ Metoda }} & \multicolumn{3}{|c|}{ Syarat } & \multirow{2}{*}{ Hasil } \\
\hline & & & & Min & & Max & \\
\hline 1 & Penetrasi (25oC, 5 detik) & & )6-2456-1991 & 60 & & 79 & 70.083 \\
\hline 2 & Titik Lembek & & $6-2434-1991$ & 48 & & 58 & 55 \\
\hline 3 & Titik Nyala & & 66-2433-1991 & 200 & & 0 & 209 \\
\hline 4 & Daktilitas $(25 \mathrm{oC}, 5 \mathrm{~cm} /$ menit $)$ & & $6-2432-1991$ & 100 & & - & 124 \\
\hline 5 & Kehilangan Berat & & 66-2440-1991 & - & & 0,8 & 0,038 \\
\hline 6 & Berat Jenis & SN & $06-2432-1991$ & 1 & & - & 1.029 \\
\hline
\end{tabular}

Jurnal APLIKASI: Media Informasi \& Komunikasi Aplikasi Teknik Sipil Terkini Halaman 23 


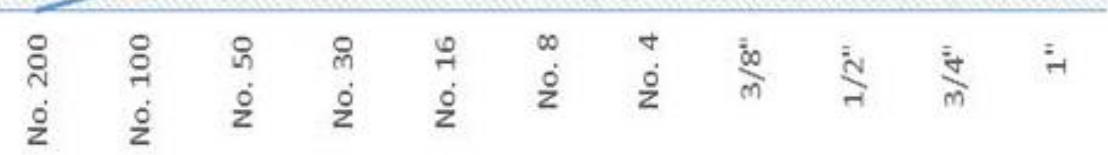

Gambar 1. Hasil pengujian gradasi pasir Seruyan

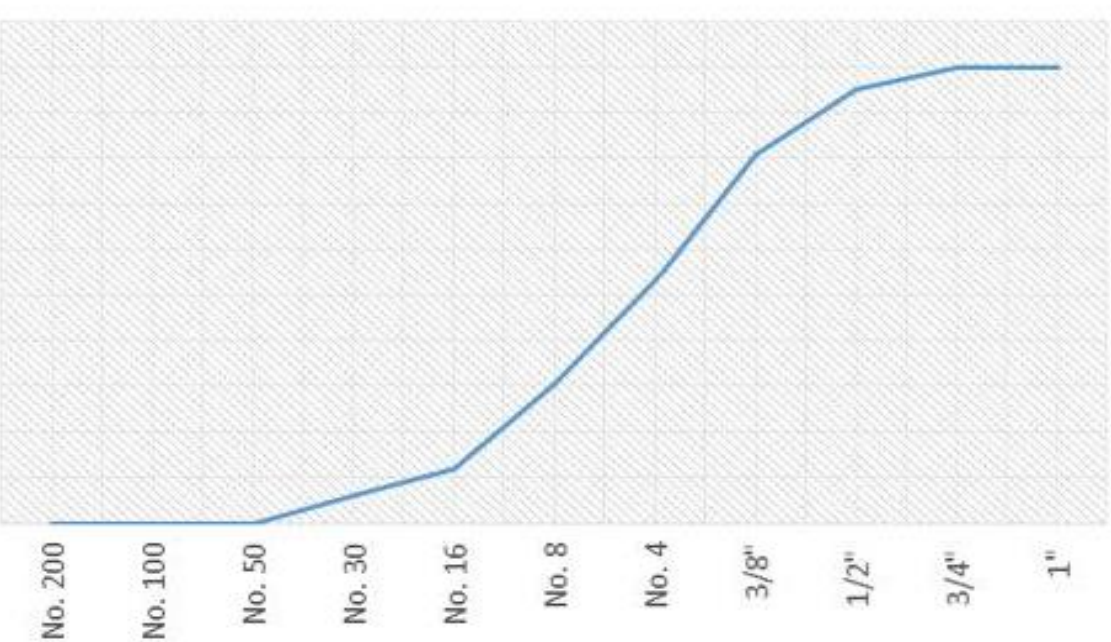

Gambar 2. Hasil pengujian gradasi aggregat kasar

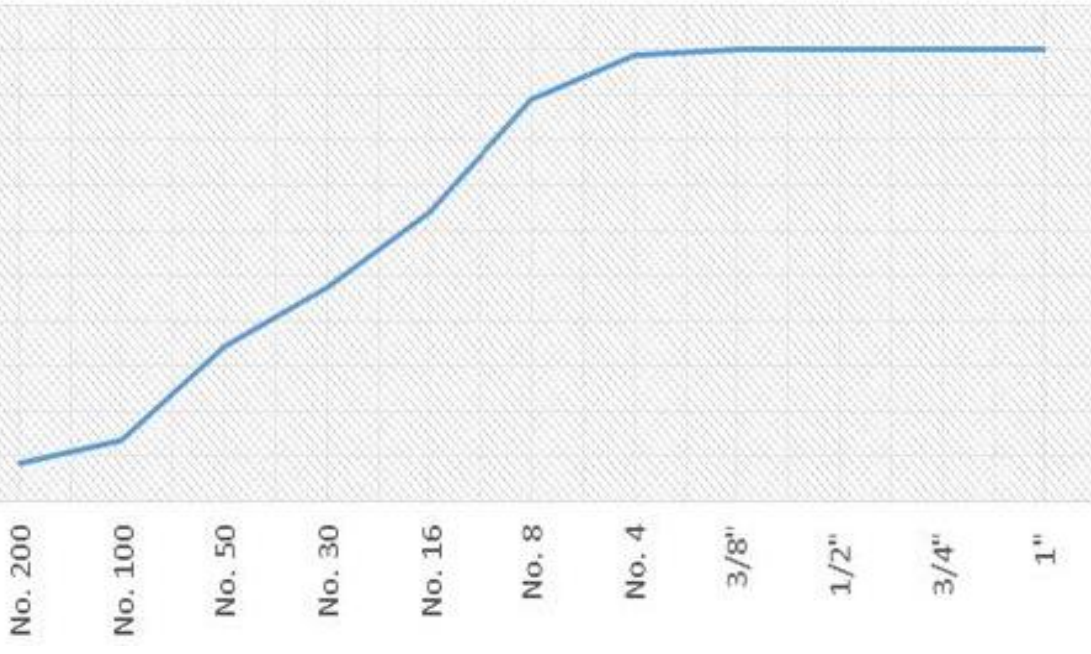

Gambar 3. Hasil pengujian gradasi abu batu 


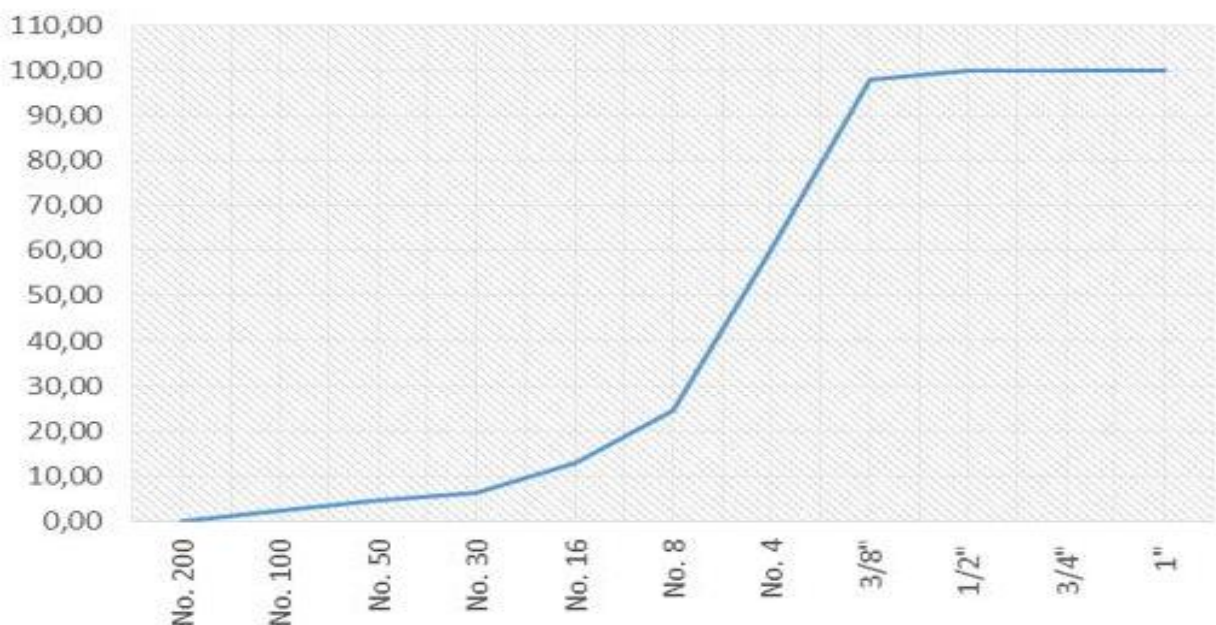

Gambar 4. Hasil pengujian gradasi aggregat sedang

Tabel 3. Spesifikasi \% lolos Aggregat kasar, Pasir Seruyan, dan filler

\begin{tabular}{ccccccccc}
\hline \multirow{3}{*}{ NO } & \multicolumn{2}{l}{ Aggregat Kasar } & \multicolumn{2}{c}{ Pasir Seruyan } & \multicolumn{2}{c}{ Filler } \\
& $\%$ Lolos & $79 \%$ & \% Lolos & $15 \%$ & $\%$ Lolos & $6 \%$ & Total & Spesifikasi \\
\hline $3 / 4$ & 100,00 & 79,00 & 100,00 & 15,00 & 100 & 6 & 100,00 & 100,00 \\
$1 / 2$ & 95,00 & 75,05 & 100,00 & 15,00 & 100 & 6 & 96,05 & $90-100$ \\
$3 / 8$ & 81,00 & 63,99 & 100,00 & 15,00 & 100 & 6 & 84,99 & $72-90$ \\
4 & 53,00 & 41,87 & 100,00 & 15,00 & 100 & 6 & 62,87 & $43-63$ \\
8 & 30,50 & 24,10 & 99,60 & 14,94 & 100 & 6 & 45,04 & $28-39.1$ \\
16 & 12,00 & 9,48 & 94,33 & 14,15 & 100 & 6 & 29,63 & $19-25.6$ \\
30 & 6,12 & 4,83 & 84,33 & 12,65 & 100 & 6 & 23,48 & $13-19.1$ \\
50 & 0,00 & 0 & 38,80 & 5,82 & 100 & 6 & 11,82 & $9-15.5$ \\
100 & 0,00 & 0 & 6,74 & 1,01 & 100 & 6 & 7,01 & $6-13$ \\
200 & 0,00 & 0 & 0,13 & 0,02 & 98,8 & 5,93 & 5,95 & $4-10$ \\
\hline
\end{tabular}

Tabel 4. Spesifikasi \% lolos Aggregat kasar, Aggregat halus, Filler, dan Aggregat sedang

\begin{tabular}{|c|c|c|c|c|c|c|c|c|c|c|}
\hline \multirow{2}{*}{ No } & \multicolumn{2}{|c|}{$\begin{array}{l}\text { Aggregat Kasar } \\
\text { PT. Merakindo Mix }\end{array}$} & \multicolumn{2}{|c|}{$\begin{array}{l}\text { Agregat Halus } \\
\text { Pasir Seruyan }\end{array}$} & \multicolumn{2}{|c|}{$\begin{array}{c}\text { Filler } \\
\text { Semen Portland }\end{array}$} & \multicolumn{2}{|c|}{$\begin{array}{l}\text { Aggregat Sedang } \\
\text { PT. Merakindo Mix }\end{array}$} & \multirow{2}{*}{ Total } & \multirow{2}{*}{$\begin{array}{l}\text { SpesifikASI } \\
\text { AC WC Kasar } \\
2010\end{array}$} \\
\hline & \% Lolos & $50,00 \%$ & \% Lolos & $7,00 \%$ & \% Lolos & $6,00 \%$ & \% Lolos & $37,00 \%$ & & \\
\hline $3 / 4$ & 100,00 & 50,00 & 100,00 & 7,00 & 100 & 6 & 100,00 & 37,00 & 100,00 & 100,00 \\
\hline $1 / 2$ & 95,00 & 47,50 & 100,00 & 7,00 & 100 & 6 & 100,00 & 37,00 & 97,50 & $90-100$ \\
\hline $3 / 8$ & 81,00 & 40,50 & 100,00 & 7,00 & 100 & 6 & 98,00 & 36,26 & 89,76 & $72-90$ \\
\hline 4 & 53,00 & 26,50 & 100,00 & 7,00 & 100 & 6 & 60,23 & 22,29 & 61,79 & $43-63$ \\
\hline 8 & 30,50 & 15,25 & 99,60 & 6,97 & 100 & 6 & 24,44 & 9,04 & 37,26 & $28-39.1$ \\
\hline 16 & 12,00 & 6,00 & 94,33 & 6,60 & 100 & 6 & 12,78 & 4,73 & 23,33 & $19-25.6$ \\
\hline 30 & 6,12 & 3,06 & 84,33 & 5,90 & 100 & 6 & 6,12 & 2,26 & 17,23 & $13-19.1$ \\
\hline 50 & 0,00 & 0 & 38,80 & 2,72 & 100 & 6 & 4,59 & 1,70 & 10,41 & $9-15.5$ \\
\hline 100 & 0,00 & 0 & 6,74 & 0,47 & 100 & 6 & 2,18 & 0,81 & 7,28 & $6-13$ \\
\hline 200 & 0,00 & 0 & 0,13 & 0,01 & 98,8 & 6 & 0,00 & 0,00 & 5,94 & $4-10$ \\
\hline
\end{tabular}


Perancangan proporsi aggregat gabungan dilakukan dengan cara:

1. Dengan cara grafis kotak bujur sangkar hasilnya tidak memenuhi specifikasi campuran AC WC gradasi kasar.

2. Dengan cara analitis

$\mathrm{P}=\mathrm{aA}+\mathrm{bB}+\mathrm{cC}$

$\mathrm{P}=$ persen lolos saringan dengan bukaan $\mathrm{d} \mathrm{mm}$ yang diinginkan diperoleh specifikasi campuran.

$\mathrm{A}=$ persen lolos saringan fraksi agregat kasar untuk bukaan d $\mathrm{mm}$

$\mathrm{B}=$ persen lolos saringan fraksi agregat Halus (Pasir Seruyan) untuk bukaan $\mathrm{d}$ mm

$\mathrm{C}=$ persen lolos saringan fraksi Filler (Semend Portland) untuk bukaan d

$\mathrm{a}=$ proporsi dari fraksi agregat kasar

$\mathrm{b}=$ proporsi dari fraksi agregat Halus (Pasir Seruyan) $\mathrm{c}=$ proporsi dari fraksi Filler (Semend Portland)

Nilai a, b, c diperoleh dengan "trial and error" karena perhitungan $\mathrm{P}$ dengan cara grafis 2 fraksi agregat kasar dan halus (Pasir Seruyan) di atas dengan Nomor saringan 50,100 dan 200 tidak memenuhi spesifikasi campuran AC WC gradasi kasar, maka ditambah filler sebagaimana ditunjukan pada Tabel 3.

Kadar aspal optimum adalah jumlah aspal yang digunakan dalam campuran agar dapat tercapai mencapai persyaratan Stabilitas, Flow, VMA, VIM, VFA, dan Marshall Quotient. Penentuan kadar aspal optimum untuk menetepkan besarnya kadar aspal efektif dalam campuran yang diperlukan untuk pembuatan benda uji baru dengan komposisi agregat sama tetapi dengan kadar aspal optimum yang telah ditentukan, seperti pada Gambar 5 .

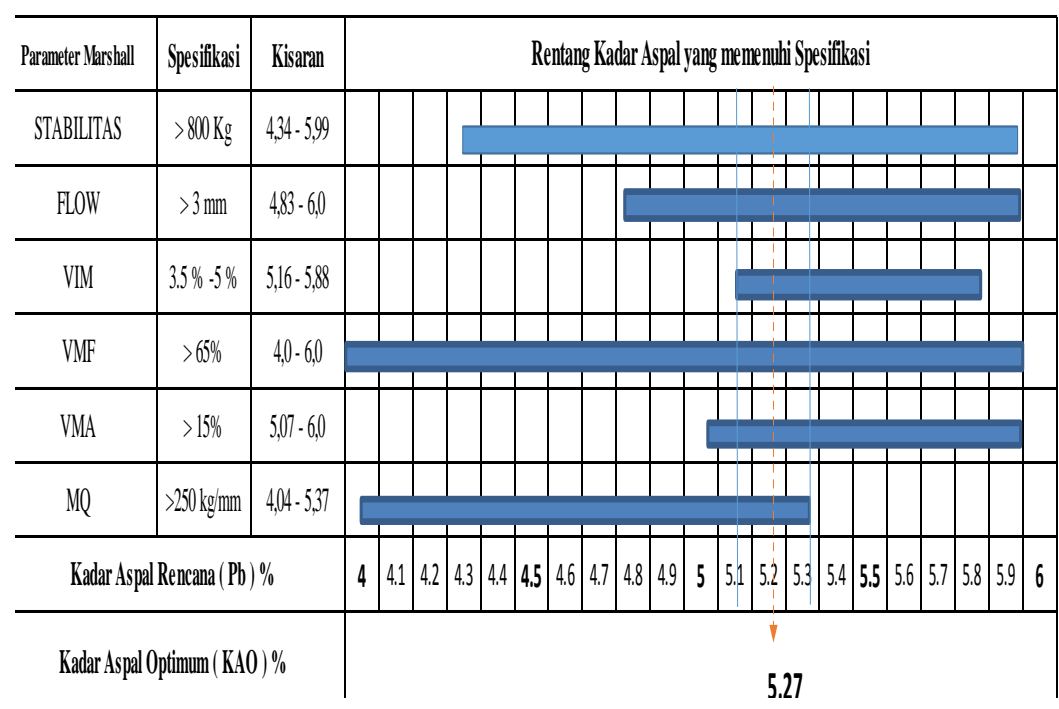

Gambar 5. Kadar aspal optimum 
1). Kadar aspal 4,34\% sampai $5,99 \%$ memenuhi syarat nilai stabilitas

2). Pada kadar Aspal 4,83\%, sampai $6,0 \%$ memenuhi persyaratan nilai Flow yang ditentukan.

3) Nilai VIM memenuhi syarat pada kadar aspal 5,16\% sampai 5,88\%

4) Nilai VFA memenuhi syarat pada kadar aspal 4,0\% sampai $6,0 \%$
5) Nilai VMA yang memenuhi syarat yaitu pada kadar aspal 5,07\% sampai $6,0 \%$.

6) Nilai MQ yang memenuhi syarat yaitu pada kadar aspal $4,04 \%$ sampai $5,41 \%$

7) Pada nilai KAO (Kadar Aspal Optimum) kadar aspal 5,27\% memenuhi semua persyaratan Stabilitas, Flow, VIM, VMF, VMA, dan MQ.

Tabel 5. Hasil pengujian Marshall

\begin{tabular}{llllllll}
\hline No & Jenis Pemeriksaan & Spesifikasi & \multicolumn{5}{c}{ Kadar aspal (\%) } \\
& & & 4 & 4,5 & 5 & 5,5 & 6 \\
\hline 1 & VMA (\%) & $>15$ & 11,37 & 11,50 & 12,34 & 12,38 & 13,31 \\
2 & VFA (\%) & $>65$ & 94,44 & 97,41 & 94,60 & 98,42 & 94,58 \\
3 & VIM (\%) & $3,5-5$ & 0,63 & 1,18 & 0,69 & 0,20 & 0,73 \\
4 & Stabilitas (kg) & $>800$ & 595,55 & 893,33 & 554,00 & 671,73 & 740,98 \\
5 & Flow (mm) & $>3$ & 2,80 & 1,75 & 3,73 & 2,95 & 3,64 \\
6 & MQ $(\mathrm{kg} / \mathrm{mm})$ & $>250$ & 213,07 & 510,42 & 148,51 & 227,99 & 204,28 \\
\hline
\end{tabular}

Tabel 6. Hasil Pengujian Marshall Pada Kadar Aspal Optimum (KAO)

\begin{tabular}{lccccccc}
\hline \multirow{2}{*}{ Benda uji } & KAO & Stabilitas & Flow & VIM & VMF & VMA & MQ \\
& $\%$ & $\mathrm{~kg}$ & $\mathrm{~mm}$ & $\%$ & $\%$ & $\%$ & $\mathrm{Kg} / \mathrm{mm}$ \\
\hline 1 & 5,27 & 1218,80 & 3,21 & 4,20 & 71,99 & 15,00 & 379,69 \\
2 & 5,27 & 1121,85 & 3,85 & 4,50 & 70,42 & 15,28 & 291,39 \\
\hline Rata-rata & & 1170,33 & 3,53 & 4,36 & 71,20 & 15,14 & 335,54 \\
\hline
\end{tabular}

Hasil pengujian marshall terhadap campuran beton aspal panas yaitu nilai stabilitas (stability), VMA ,VMF,VIM, kelelehan (flow) dan Marshall Quotient (MQ) pada benda uji masing-masing kadar aspal 2 buah benda uji. Untuk mendapatkan nilai karakteristik aspal yang memenuhi semua persyaratan spesifikasi Revisi SNI 06-2489-1991, maka perlu dicari kadar aspal optimum ditentukan dengan cara percobaan pengujian marshall dengan variasi kadar aspal 4\%; 4,5\%; 5\%; 5,5\%; 6\%. Hasil pengujian Marshall untuk menentukan kadar aspal optimum seperti ditunjukkan pada Tabel 5.

\section{Simpulan}

Dari pengujian yang telah dilakukan terhadap bahan-bahan dasar campuran aspal beton dalam penelitian ini, dapat disimpulkan bahwa: 
1. Penggunaan Pasir Seruyan Kabupaten Seruyan Provinsi Kalimantan Tengah sebagai campuran aspal beton ini mempunyai sifat sifat fisik antara lain berat jenis 2,519 $\mathrm{gram} / \mathrm{cm}^{3}$, penyerapan airnya $1,012 \%$, sedangkan jenis gradasinya dapat di katagorikan bergradasi seragam, seperti yang terlihat di grafik gradasi pada Gambar 1 oleh karena itu dapat digunakan untuk lapis perkerasan Aspal Beton AC WC karena telah memenuhi spesifikasi terhadap setiap pengujiannya.

2. Hasil kombinasi agregatnya yaitu 6\% untuk fraksi agregat halus Pasir Seruyan, 65,80\% untuk fraksi agregat Kasar, 22,20\% untuk fraksi Abu Batu, dan 6\% untuk fraksi filler.

3. Dari hasil pengujian Marshall diperoleh grafik hubungan parameter campuran aspal beton, dengan kadar aspal optimum 5,27\%.

\section{Daftar Pustaka}

Departemen Pekerjaan Umum, Spesifikasi Umum. (2010). Bidang Jalan dan Jembatan Divisi VI. Perkerasan Beraspal.

Departemen Pekerjaan Umum, Badan Penelitian dan Pengembangan PU., (1990). Standar Nasional Indonesia, cara uji berat jenis dan penyerapan air agregat kasar, SNI 03-1969-1990.

Departemen Pekerjaan Umum, Badan Penelitian dan Pengembangan PU., (1991). Standar Nasional Indonesia, Metode Pengujian keausan agregat dengan mesin Los Angeles, SNI 03-2417-1991.
Departemen Pekerjaan Umum, Badan Penelitian dan Pengembangan PU., (1990). Standar Nasional Indonesia, metode pengujian tentang analisa saringan agregat halus dan kasar, SNI 03-1968-1990.

Departemen Pekerjaan Umum, Badan Penelitian dan Pengembangan PU., (1990). Standar Nasional Indonesia, cara uji berat jenis dan penyerapan air agregat halus, SNI 03-1970-1990.

Departemen Pekerjaan Umum, Badan Penelitian dan Pengembangan PU., (1991). Standar Nasional Indonesia, Metode Pengujian penetrasi bahan-bahan Bitumen, SNI 06-2456-1991.

Departemen Pekerjaan Umum, Badan Penelitian dan Pengembangan PU., (1991). Standar Nasional Indonesia, cara uji titik lembek dengan alat cincin dan bola, SNI 06-2434-1991.

Departemen Pekerjaan Umum, Badan Penelitian dan Pengembangan PU, Standar Nasional Indonesia, metode pengujian titik nyala dan titik bakar dengan cleve land oven cup, SNI 06-2433-1991.

Departemen Pekerjaan Umum, Badan Penelitian dan Pengembangan PU, Standar Nasional Indonesia, metode pengujian Daktilitas bahan bahan aspal, SNI 06-2432-1991.

Departemen Pekerjaan Umum, Badan Penelitian dan Pengembangan PU, Standar Nasional Indonesia, metode pengujian kehilangan berat minyak dan aspal dengan cara A, SNI 06-2440-1991. 
Departemen Pekerjaan Umum, Badan Penelitian dan Pengembangan PU, Standar Nasional Indonesia, metode pengujian berat jenis aspal padat, SNI 06-2441-1991.

Departemen Pekerjaan Umum, Badan Penelitian dan Pengembangan PU, Standar Nasional Indonesia, metode pengujian campuran aspal dengan alat marshall, SNI 06-24891991.

Sukirman, S, 2003. Beton Aspal Campuran Panas. Granit: Jakarta.

Utomo, A, 2008. Studi Komparasi Pengaruh Gradasi Gabungan Dilaboratorium dan Gradasi Hot Bin AMP campuran Laston (AC Wearing Course) Terhadap karateristik Uji Marshall. Tesis. Semarang. 
